\title{
A randomized-controlled pilot study on the effects of naproxen for the treatment of bleeding and spotting among new Copper T 380A IUD users
}

\author{
Emily M Godfrey ( $\sim$ godfreye@uw.edu ) \\ University of Washington https://orcid.org/0000-0003-2408-7828 \\ C. Holly A. Andrilla \\ University of Washington \\ Katherine Odem-Davis \\ Seattle Children's Research Institute
}

\section{Research article}

Keywords: copper intrauterine device, heavy menstrual bleeding, non-steroidal anti-inflammatory drug, treatment, naproxen sodium

Posted Date: August 20th, 2020

DOI: https://doi.org/10.21203/rs.3.rs-45458/v1

License: (c) (i) This work is licensed under a Creative Commons Attribution 4.0 International License. Read Full License 


\section{Abstract}

Background: The most common reason women report discontinued use of the Copper T 380A (TCu380A) IUD is because of bleeding irregularities after method initiation. The objective of this study was to determine whether an over-the-counter NSAID, naproxen sodium, reduces the number of bleeding and spotting days and heavy or prolonged bleeding episodes among new users of the TCu380A IUD compared to placebo.

Methods: In this double-blind pilot trial, we randomized 28 new TCu380A IUD users who reported menstrual cycle changes within 4-6 weeks after IUD placement to either naproxen $440 \mathrm{mg}$ or placebo twice daily for 7 days for three consecutive 28-day cycles and one additional 28 -day cycle without treatment. Participants completed a daily bleeding and other symptom diary, and monthly questionnaires.

Results: Although not statistically significant, participants in the naproxen arm reported more mean number of spotting-only days during the three treatment cycles compared those in the placebo group (13.5 days (SE 5.1) vs.7.5 days (SE 1.7), respectively). Otherwise, the mean number of bleeding-only days during treatment and post-treatment and spotting-only post-treatment were similar between the groups. During each treatment cycle, fewer participants in the treatment group reported heavy bleeding compared to placebo group (30.7\% fewer in cycle $2 ; 5.4 \%$ fewer in cycle 3 ). More women in the treatment group, however, reported prolonged menstrual bleeding of greater than 7 days for each cycle, although the percentage reporting prolonged bleeding decreased each consecutive treatment and post-treatment cycle $(+27.5 \%,+19.8 \%,+9.1 \%,+4.5 \%$, cycles $1-4$ respectively). Other symptoms experienced by new TCu380A users did not differ between the study arms.

Conclusions: Treatment with naproxen did not significantly reduce the number of bleeding or spotting days among new TCu380A users. Although not statistically different, proportionally fewer participants in the naproxen group reported moderate-heavy or heavy periods, but more reported prolonged menstrual bleeding compared to placebo. Participants tolerated oral naproxen use well.

Trial registration: ClinicalTrials.gov: NCT02519231. Registered on August 102015.

\section{Background}

Intrauterine devices (IUDs) are among the most widely used reversible contraceptive methods in the world [1]. In the U.S., IUD use is on the rise, with several million women currently using the method [2]. Copper-containing IUDs (Cu-IUD) were introduced into worldwide markets in the late 1960s and are available in a variety of types, most of which are named for their shape and amount of copper on the device. The Cu-IUD is considered nonhormonal, which is important especially for women with underlying medical conditions for which hormone-related contraceptives are contraindicated. Currently, the Copper T 380A (TCu380A) is the sole Cu-IUD available in the U.S. and is approved for use for 10 years, although effectiveness for up to 12 years has been shown [3].

Despite its growth in popularity in the U.S., approximately $11 \%$ of women who have a TCu380A IUD inserted will discontinue the method within the 6months of use [4]. The most common reasons for Cu-IUD and TCu380A discontinuation are bleeding irregularities and dysmenorrhea [5]. TCu380A IUD users who report increased menstrual bleeding during the first year of IUD use are two times more likely to prematurely discontinue their method than hormonal levonorgestrel IUD users [6].

Because of the commonality of perceived heavy or prolonged menstrual bleeding among Cu-IUD users, a number of treatments have been studied. However, few of these studies have included TCu380A. In a prior systematic review that evaluated 11 studies for acute treatment for Cu-IUD users with underlying unscheduled spotting or bleeding or heavy bleeding, none appeared to include the TCu380A [7]. Among treatments for unscheduled bleeding or for treatment of heavy menstrual bleeding, non-steroidal anti-inflammatory drugs (NSAIDs) are the most widely studied. The applicability to U.S. women of findings from this systematic review is limited though because most NSAIDs studied were either non-FDA-approved or were made available by prescription only [7]. A study that includes an over-the-counter (OTC) NSAID medication, such as naproxen, as potential treatment for heavy or prolonged bleeding or spotting during TCu380A use could affect continuation among TCu380A users.

\section{Methods}

The objective of this pilot study was to determine whether an OTC NSAID, naproxen sodium, reduces heavy and prolonged bleeding in new users of the TCu380A IUD. We hypothesized that TCu380A users randomized to the OTC $(440 \mathrm{mg})$ naproxen group would have fewer bleeding and spotting days each month compared to users randomized to the placebo group. We conducted this trial in accordance with the Consolidated Standards of Reporting Trials (CONSORT) guidelines [8].

This prospective, double-blind, parallel-arm randomized placebo-controlled, phase IV pilot study included a 4-week screening phase, followed by a 12-week intervention period and a subsequent 4-week observation period. This study was conducted at the University of Washington in Seattle, WA, USA. The primary outcome of this trial was the number of bleeding and/or spotting days over the 3-month (84-day) treatment period, based on diary data received from the participants. To be included in the study, potential participants had to be English speaking, aged $\geq 18$ and $<49$ years, have regular menstrual cycles ranging from 21-35 days, and be within 7 days of TCu380A IUD placement. Exclusion criteria included known or suspected pregnancy, NSAID allergy, regular NSAID use to treat a chronic health condition, diagnosis of menorrhagia, metrorrhagia, symptomatic uterine 
fibroids, or endometrial polyps, use of depo-medroxyprogesterone acetate or hormonal IUD within the last three months, vaginal or cesarean birth in the last four weeks, breastfeeding, or prior TuC380A IUD use.

\section{Recruitment}

We recruited participants with advertisements and automated weekly reports using Current Procedural Terminology codes and device $\mathrm{J}$ codes (J7300) of patients aged 18-49 years who received a TCU380A IUD at one of the UW-affiliated health clinics within the prior week. From these reports, research staff called potential participants to inform them about the study, and if interested, reviewed the study eligibility criteria. Potential participants who met the eligibility criteria were scheduled for a study visit within 7 days of their TCu380A IUD insertion.

Once consented, enrolled participants completed several baseline questionnaires that included contact and demographic information, medical history, menstrual and pelvic pain history questions adapted from the World Endometriosis Foundation (WERF-EPHect Questionnaire) [9]. Study data were collected using REDCap (Research Electronic Data Capture) a secure, web-based application designed to support data capture for research studies [10].

\section{Subject Randomization}

Research staff contacted enrolled participants 4-6 weeks after their TCu380A IUD insertion to determine eligibility for randomization to a treatment arm. Participants were eligible to be randomized if they reported any change in menstrual bleeding since their TCu380A IUD insertion, were willing to forgo the use of NSAIDs for the remainder of the study other than the assigned study medication, and were able to complete a daily bleeding diary.

The UW Investigational Drug Service (IDS) assigned the treatment arm using a 4-block 1:1 randomization scheme. Kelley-Ross pharmacy in Seattle, WA compounded the study medication and delivered it directly to IDS for packaging. IDS labeled all study medication bottles, regardless of allocated cohort, as $440 \mathrm{mg}$ naproxen-sodium tablets in order to maintain double-blinding.

Randomized study participants received their study drug, either $440 \mathrm{mg}$ naproxen sodium or identical placebo capsule, which was to be taken the first day of their next menstrual period, twice daily for 7 days during three consecutive cycles. Each cycle was defined as 28 days [11]. During the fourth cycle, participants did not take any study medication, but continued to complete a daily bleeding diary. We chose 7 consecutive days because this is consistent with current U.S. national contraceptive guidelines for NSAID treatment of unscheduled spotting or light bleeding or heavy or prolonged menstrual bleeding with Cu-IUD use [12]

Bleeding Diary

Participants tracked their daily bleeding, medication use and side effects on paper diaries along with daily text messages (Mir3, San Diego, CA, USA, or using the "Clue" tracking smartphone application, a free, period-tracking app available through Apple or Google-Play [13].

\section{Monthly Phone Calls}

Study staff called participants monthly to complete a questionnaire about study medication intake, IUD removal or expulsion, last menstrual period duration and flow, expected and unexpected vaginal bleeding or spotting in the last month, and any adverse events. Questions about menstruation were adapted from the St. Louis CHOICE project questionnaire [14]. Definition of heavy flow was based on the participants' subjective experience of flow as "light," "moderate," or "heavy" compared to their menstrual flow just prior to their TCu380A insertion.

\section{Final 6-month Study Visit}

The final study visit was scheduled 6 months after each participant's IUD insertion. Participants returned their study medication bottles and any unused study medication, and submitted their completed paper bleeding diaries. Participants completed the same menstrual questionnaires as were used at baseline, along with 6-month satisfaction and TCu380A IUD continuation questionnaires.

\section{Safety Assessment}

A meta-analysis found that OTC naproxen sodium is as safe as ibuprofen, acetaminophen, and placebo and that there is no evidence of overall dose-related increase in adverse events $[15,16]$. Nonetheless, study staff informed participants at the start of the study that they were to report all adverse events or concerns related to the treatment. Study staff queried each participant during monthly calls for side effects that may require modification of the intervention. Specifically, participants were assessed for gastrointestinal, cardiovascular or hepatic effects and allergic reactions. Each participant was advised to contact the research site immediately if any significant medical problems or complaints occurred during the study. The PI, a family planning-trained family physician, was available 24 hours a day and able to evaluate all complaints and assure that appropriate health care or referral was provided for all study participants. Adverse events were defined by federal regulations as any new medical problem or exacerbation of an existing problem experienced by a participant while enrolled in the study, whether or not it was considered treatment related by the investigator. 
We originally planned to enroll 60 subjects based on other similar studies that evaluated treatment for bleeding among women using contraception [17-19]; as reported by Cohen et al. [17], a sample size of 42 provided $80 \%$ power to detect a difference of 7 bleeding/spotting days in 30 days by two-sample t-test, allowing for an expected $20 \%$ drop-out. We designed the study to include another site, in addition to the UW site enrolled participants. After 6 months of failed active recruitment at the other site, we discontinued that site from the study. Resources did not permit us to contract with an alternative recruitment site, and thus the protocol was revised to enroll 32 participants at the Seattle site only.

\subsection{Statistical Analysis}

We compared baseline characteristics of the women in the naproxen and placebo groups using Chi-squared, Fisher's Exact, and independent-t-tests as appropriate (Table 1). For days with bleeding/spotting outcomes (Table 2), we used independent t-tests to compare the unadjusted mean difference between the naproxen and placebo groups. Bleeding was defined as any bleeding that requires $>1$ panty liner, tampon, or pad in a day. Spotting was defined as minimal blood loss that requires 1 or no use of any protection including panty liners. Bleeding episodes were defined as days of bleeding or spotting that were bounded by 2 days of no bleeding or spotting. Bleeding/spotting episodes were classified by the following bleeding pattern: prolonged (i.e., length of a single bleeding/spotting episode 14 days or more per 84 -day reference period), frequent (more than 5 bleeding/spotting episodes per 84-day reference period), infrequent (i.e., less than 3 bleeding/spotting episodes per 84 -day reference period) or amenorrhea (i.e., absence of bleeding/spotting for at least 84 consecutive days). Participants who reported a 14-day episode and more than 5 episodes within a 84-day period were classified as "both prolonged and frequent bleeding." Subjects who reported between 3-5 bleeding/spotting episodes were considered as having a "normal" bleeding pattern. We calculated a change in the number of days bleeding/spotting, spotting-only, bleeding-only in study months 1 through 3 and at baseline by subtracting three times each participant's reported baseline monthly days of bleeding from their reported bleeding/spotting, spotting-only, bleeding-only in study months 1 through 3 . We compared differences between the treatment groups using independent t-tests, assuming unequal variances.

We calculated the proportion of women who reported heavy bleeding, frequent cramping, extended menstrual bleeding and unexpected bleeding on their monthly questionnaires, and compared the naproxen and placebo groups using chi-square and Fisher exact tests (Table 3 ). We calculated the number of days in which a woman reported each potential side effect during the treatment months (months 1-3) and compared the resulting means of the naproxen and placebo groups using a two-sided independent t-test (Table 4). For analysis of satisfaction, we calculated median satisfaction score and interquartile range (Table 5). We analyzed participants in their assigned treatment group. Participants who had missing bleeding diary data were excluded from the analysis. Analyses were conducted using SAS version 9.4 (SAS Institute, Inc., Cary, NC). Nominal p-values are reported without adjustment for multiple comparisons.

\section{Results}

Between February 2016 and May 2017, 34 women enrolled into the study, of whom 28 were randomized one month after TCu380A insertion. Twenty-five participants completed all four study cycles; 20 participants submitted data on bleeding. Fig. 1 depicts participant flow according to CONSORT guidelines [8]. There were no significant differences of baseline characteristics between the study arms at baseline (Table 1).

Among 20 participants who submitted their bleeding diaries, participants in the naproxen arm reported more mean number of spotting-only days during the three treatment cycles compared those in the placebo group (13.5 days (SE 5.1) vs.7.5 days (SE 1.7), respectively), although this finding was not significant (Table 2). When adjusted for baseline bleeding, naproxen participants had 0.9 bleeding-only days/cycle, or 2.7 total more bleeding-only days (95\% Cl-4.1-9.5 days) during the first 3 months and only one additional bleeding-only day during the post-treatment observational month, suggesting that naproxen did not contribute to additional days of bleeding compared to placebo.

There were no statistically significant differences between the naproxen and placebo group among the participants who responded to the monthly questionnaire about their period being heavier than baseline, lasting more than 7 days, frequent cramping or unexpected bleeding. Although not significant, fewer women in the naproxen group reported moderate-heavy or heavy periods during the second and third treatment months (-30.7\% month 2, $-5.4 \%$ month 3) (Table 3). On the other hand, more naproxen users reported menstrual bleeding length $\geq 7$ days throughout the study period, but the difference between naproxen and placebo groups narrowed with each consecutive treatment month and into the final post-treatment observational month $(+27.5 \%,+19.8 \%,+9.1 \%,+4.5 \%$, months $1-4$ respectively). Although not significant, more than $25 \%$ fewer participants reported often/always cramping in the naproxen group only during the first treatment month than the placebo group. Otherwise, complaints of cramping were similar during the second and third treatment months (Table 3). Unexpected bleeding varied throughout the study, but overall, a smaller percentage of naproxen users reported this finding than those who took placebo (Table 3).

Overall, naproxen was well tolerated by the participants. There was no statistically significant difference in the percentage of naproxen users and placebo users who reported symptoms (Table 4). Cramping was the most frequently reported side effect by women in both groups. No participants reported any major adverse outcomes during the treatment or post-treatment months. None of the women who completed the final survey discontinued their TCu380A IUD, except for a placebo group participant whose IUD fell out prior to the second treatment month of the trial. Two women, one in each group were lost to follow up and thus, their continuation status of TCu380A IUD is unknown. 
Both groups were similarly very satisfied with the TCu380A IUD, with 3=very satisfied (naproxen median score =3, IQR 2-3; placebo median score=3, IQR 2.25-3) (Table 5). Only one person, assigned to the naproxen group, was not satisfied with her IUD, due to prolonged menstruation and cramping during the second half of the cycle. The scores indicating the likelihood of continuation of the TCu380A IUD were similar between the groups.

\section{Discussion}

Some women who use the TCu380A IUD report more cramping and heavier bleeding compared to baseline during the first 3 months of use [20]. NSAIDs are the most widely studied medications for blood-loss reduction for Cu-IUD users. Evidence indicates that these medications can reduce menstrual bleeding for a current bleeding episode and may prevent heavy or prolonged menstrual bleeding [21]. Prior to this present pilot study, however, information regarding treatment with an OTC dose-equivalent NSAID medication for menstrual irregularities among new TCu380A IUD users with recent changes in menstruation was lacking. Determining whether OTC naproxen alleviates heavy or prolonged bleeding could be a simple and accessible intervention to improve associated bleeding and cramping of this popular and highly effective contraceptive method.

In this double-blinded pilot RCT, we randomized 28 new TCu380A IUD users who had reported menstrual changes after their first month of use to determine whether naproxen $440 \mathrm{mg}$ twice daily ( $880 \mathrm{mg} /$ day) for 7 days during three consecutive menstrual cycles decreased overall number of days of bleeding/spotting, bleeding-only or spotting-only days compared to placebo. Among the 20 women who submitted their bleeding diaries, we found no significant differences between reported number bleeding/spotting, bleeding-only or spotting-only days between the groups. Among the larger group of participants, we also found no significant differences among the study participants' reporting moderately-heavy/heavy menstruation, prolonged bleeding, cramping or unexpected bleeding. Nonetheless, with each consecutive month of NSAID use, heavy menstruation, prolonged bleeding and unscheduled bleeding appeared to improve. A handful of small studies have evaluated the use of different types of NSAIDs, including naproxen, to treat heavy or prolonged menstruation in the presence of Cu-IUDs, with results favoring reduction in measured menstrual blood loss [2225]. Similar to our findings, two prior studies found no statistically significant differences between naproxen and placebo among IUD users regarding participants' self-reports of menstrual bleeding flow and duration [26, 27]. Less consistent with other findings, we found fewer participants in the naproxen group reported often/always cramping only in the first treatment month compared to placebo [21].

Despite the body of evidence suggesting that NSAIDs treat menstrual blood loss among Cu-IUD users, the variation by which menstrual blood loss is measured makes comparisons with our findings difficult [28]. Most prior studies used an objective measure of menstrual blood loss, which requires the burdensome task of study participants saving their used sanitary pads and transporting them back to the research team for processing by alkaline hematin technique [7]. Similar to more recent studies, our study utilized standardized methods of collecting and analyzing bleeding/spotting days [10]. Although subjective reporting of heavy menstrual bleeding has been shown to have limited accuracy, it remains important from the standpoint of the woman's perspective. Prior research suggests women who perceive a change to heavier blood loss or greater bleeding frequency with TCu380A IUD use are less likely to be satisfied with their method [20]. What is reassuring, however, is that to our knowledge no women in our study discontinued their TCu380A IUD method, except for a participant who reported it had fallen out. A growing body of evidence suggests that TCu380A IUD users continue their method at similar rates as other long-acting reversible methods, including those reporting heavy menses prior to insertion $[6,29,30]$.

Strengths of our study include baseline similarities between study participants, as all randomized participants were first time TCu380A IUD users and reported changes in their bleeding pattern within their first month of use. A limitation includes our small sample size, which did not provide sufficient power to detect differences between the groups. We were surprised by our difficulty with recruitment. We made considerable effort to identify potential participants at the Seattle site by receiving weekly notifications of women who had received a TCu380A IUD within our health system. The vast majority of women whom we "cold-called" about the study never responded. Our success was even less successful at our other potential recruitment site, where all women approached declined to participate in the study. While reasons for declining enrollment are not known, we believe that one barrier could have been that new TCu380A users did not want to forgo NSAID use after getting their method. Another potential barrier in Seattle was that women had to transport themselves to another location to pick up the study medication, since pharmacy dispensing laws in Washington State for research purposes did not allow the UW IDS to mail the pills either to enrolled participants' homes or to the clinical sites where baseline questionnaires were completed. Another limitation was missing bleeding diaries, occurring among more than $40 \%$ of placebo users and $15 \%$ of naproxen users. Because of the considerable missing data, there was not enough bleeding data to impute expected bleeding/spotting days. Thus, our findings should be interpreted with caution.

\section{Conclusions}

The results of this study did not support our hypothesis that OTC (440 mg) naproxen would result in fewer bleeding and spotting days each month among new TCu380A users over a 3-month period. There were too few subjects to provide adequate power to determine differences between bleeding and spotting among naproxen and placebo groups. Based on the findings and limitations of this study, further research is needed. An ideal study would entail a 3-arm comparison: tranexamic acid, naproxen and placebo. Antifibrinolytic agents, which help prevent the disintegration of blood clots, have shown superior improvement of heavy menstrual bleeding over NSAIDs among non-IUD users [31]. Additional outcomes, such as satisfaction, quality of life and method continuation through the first year of use would lend itself to a more robust study. 


\section{Abbreviations}

B/S=bleeding and/or spotting; CONSORT=CONsolidated Standards of Reporting Trials; IDS= Investigational Drug Service; IUD=intrauterine device; mg=milligrams; NSAIDS= non-steroidal anti-inflammatory drugs; OTC= over-the-counter; REDCap=Research Electronic Data Capture; SAS=Statistical Analysis Software; SE=standard error; TCu380A=Copper T 380A intrauterine device

\section{Declarations}

Ethics approval and consent to participate: The Human Subjects Review Board of the University of Washington (UW) approved this study (ID: STUDY00000323). All study requirements and procedures were explained to potential participants, and each participant provided written informed consent.

Consent for publication: Not applicable

Availability of data and materials: All datasets used and analysed during the current study are available from the corresponding author on reasonable request.

Competing interests: The authors declare that they have no competing interests.

Funding: This study was supported in part by an Independent Investigator Research Award from CooperSurgical, Inc. The study sponsor played no role in the study design, collection analysis and interpretation of data; writing of report; and in the decision to submit the paper for publication. REDCap database support was provided by the National Center for Advancing Translational Sciences of the National Institutes of Health under Award Number UL1 TR002319. The findings and conclusions are those of the authors and do not necessarily represent the views and opinions of CooperSurgical, Inc. or the National Institutes of Health.

Authors' contributions: EMG was the Principal Investigator for the study. EMG conceived the study, oversaw the enrollment of participants and assisted with data analysis. KOD contributed to study statistical planning. CHA performed the data analysis. All authors contributed to manuscript preparation and critically reviewed each draft. All authors approved the final manuscript for publication.

Acknowledgements: The authors wish to thank the women who participated in this study. The authors also thank Dr. Rachel Ji-Yeon Ryu from the UW Investigational Drug Service and Ms. Kelly Gilmore from the UW Department of Obstetrics and Gynecology for their assistance with this study.

Author Information:

Department of Family Medicine, University of Washington, Box 354982, Seattle, WA 98195 USA

Emily M. Godfrey, C. Holly A. Andrilla

Department of Obstetrics and Gynecology, University of Washington, Box 356460, Seattle, WA 98195 USA

Emily M. Godfrey

Cystic Fibrosis Therapeutics Development Network Coordinating Center, Seattle Children's Research Institute, M/S CW8-5B, PO Box 5371, Seattle, WA 98145-5005, USA

Katherine Odem-Davis

Corresponding Author

Correspondence to Emily M. Godfrey

\section{References}

[1] d'Arcangues C. Worldwide use of intrauterine devices for contraception. Contraception 2007;75:S2-7.

[2] Daniels K,Abma J. Current contraceptive status among women aged 15-49: United States, 2015-2017, in NCHS Data Brief 2018, National Center for Health Statistics: Hyattsville, MD.

[3] Long-term reversible contraception. Twelve years of experience with the TCu380A and TCu220C. Contraception 1997;56:341-52.

[4] Garbers S, Haines-Stephan J, Lipton Y, Meserve A, Spieler L,Chiasson MA. Continuation of copper-containing intrauterine devices at 6 months. Contraception 2013;87:101-6. 
[5] Grunloh DS, Casner T, Secura GM, Peipert JF,Madden T. Characteristics associated with discontinuation of long-acting reversible contraception within the first 6 months of use. Obstet Gynecol 2013;122:1214-21.

[6] Rowe P, Farley T, Peregoudov A, Piaggio G, Boccard S, Landoulsi S, et al. Safety and efficacy in parous women of a 52-mg levonorgestrelmedicated intrauterine device: a 7-year randomized comparative study with the TCu380A. Contraception 2016;93:498-506.

[7] Godfrey EM, Folger SG, Jeng G, Jamieson DJ,Curtis KM. Treatment of bleeding irregularities in women with copper-containing IUDs: a systematic review. Contraception 2013;87:549-66.

[8] Moher D, Jones A, Lepage L,Group C. Use of the CONSORT statement and quality of reports of randomized trials: a comparative before-andafter evaluation. Jama 2001;285:1992-5.

[9] Vitonis AF, Vincent K, Rahmioglu N, Fassbender A, Buck Louis GM, Hummelshoj L, et al. World Endometriosis Research Foundation Endometriosis Phenome and biobanking harmonization project: II. Clinical and covariate phenotype data collection in endometriosis research. Fertil Steril 2014;102:1223-32.

[10] Harris PA, Taylor R, Thielke R, Payne J, Gonzalez N,Conde JG. Research electronic data capture (REDCap)--a metadata-driven methodology and workflow process for providing translational research informatics support. J Biomed Inform 2009;42:377-81. doi: 10.1016/j.jbi.2008.08.010. Epub Sep 30 .

[11] Mishell DR, Jr., Guillebaud J, Westhoff C, Nelson AL, Kaunitz AM, Trussell J, et al. Recommendations for standardization of data collection and analysis of bleeding in combined hormone contraceptive trials.[see comment]. Contraception 2007;75:11-5.

[12] Curtis KM, Jatlaoui TC, Tepper NK, Zapata LB, Horton LG, Jamieson DJ, et al. U.S. selected practice recommendations for contraceptive use, 2016. MMWR Recomm Rep 2016;65:1-66.

[13] Clue, URL|; Year Last Update Datel [cited Access Year Access Date]|.

[14] McNicholas C, Madden T, Secura G,Peipert JF. The contraceptive CHOICE project round up: what we did and what we learned. Clin Obstet Gynecol 2014;57:635-43.

[15] US Food and Drug Administration. NDAC Briefing Document: Review of Safety and Efficacy of OTC Naproxen Sodium. Non-prescription drug advisory committee.

[16] DeArmond B, Francisco CA, Lin JS, Huang FY, Halladay S, Bartziek RD, et al. Safety profile of over-the-counter naproxen sodium. Clin Ther 1995;17:587-601; discussion 586.

[17] Cohen MA, Simmons KB, Edelman AB,Jensen JT. Tamoxifen for the prevention of unscheduled bleeding in new users of the levonorgestrel 52mg intrauterine system: a randomized controlled trial. Contraception 2019;100:391-6.

[18] Kaneshiro B, Edelman A, Carlson NE, Nichols M, Forbes MM,Jensen J. A randomized controlled trial of subantimicrobial-dose doxycycline to prevent unscheduled bleeding with continuous oral contraceptive pill use. Contraception 2012;85:351-8.

[19] Zigler RE, Madden T, Ashby C, Wan L,McNicholas C. Ulipristal Acetate for Unscheduled Bleeding in Etonogestrel Implant Users: A Randomized Controlled Trial. Obstet Gynecol 2018;132:888-94.

[20] Diedrich JT, Desai S, Zhao Q, Secura G, Madden T,Peipert JF. Association of short-term bleeding and cramping patterns with long-acting reversible contraceptive method satisfaction. Am J Obstet Gynecol 2014;18:025.

[21] Grimes DA, Hubacher D, Lopez LM,Schulz KF. Non-steroidal anti-inflammatory drugs for heavy bleeding or pain associated with intrauterinedevice use. Cochrane Database Syst Rev 2006:CD006034.

[22] Di Lieto A, Catalano D, Miranda L,Paladini A. Action of a prostaglandin synthetase inhibitor on IUD associated uterine bleeding. Clin Exp Obstet Gynecol 1987;14:41-4.

[23] Pedron N, Lozano M,Aznar R. Treatment of hypermenorrhea with mefenamic acid in women using IUDs. Contracept Deliv Syst 1982;3:135-9.

[24] Toppozada M, Anwar M, Abdel Rahman H,Gaweesh S. Control of IUD-induced bleeding by three non-steroidal anti-inflammatory drugs. Contracept Deliv Syst 1982;3:117-25.

[25] Ylikorkala O,Viinikka L. Comparison between antifibrinolytic and antiprostaglandin treatment in the reduction of increased menstrual blood loss in women with intrauterine contraceptive devices. Br J Obstet Gynaecol 1983;90:78-83. 
[26] Davies AJ, Anderson AB,Turnbull AC. Reduction by naproxen of excessive menstrual bleeding in women using intrauterine devices. Obstet Gynecol 1981;57:74-8.

[27] Lalos O,Nilsson B. Dysmenorrhea in women with intrauterine contraceptive device. Treatment with a prostaglandin synthetase inhibitor, naproxen. Int J Gynaecol Obstet 1983;21:33-7.

[28] Magnay JL, O'Brien S, Gerlinger C,Seitz C. A systematic review of methods to measure menstrual blood loss. BMC Womens Health. 2018;18:142. doi: 10.1186/s12905-018-0627-8.

[29] Hobby JH, Zhao Q,Peipert JF. Effect of baseline menstrual bleeding pattern on copper intrauterine device continuation. Am J Obstet Gynecol 2018;219:465.e1-.e5.

[30] Sanders JN, Turok DK, Gawron LM, Law A, Wen L,Lynen R. Two-year continuation of intrauterine devices and contraceptive implants in a mixed-payer setting: a retrospective review. Am J Obstet Gynecol 2017;216:590.e1-.e8.

[31] Bryant-Smith AC, Lethaby A, Farquhar C,Hickey M. Antifibrinolytics for heavy menstrual bleeding. Cochrane Database Syst Rev. 2018;4:CD000249.:10.1002/14651858.CD000249.pub2.

\section{Tables}

\section{Table 1}

Characteristics of study participants at randomization, by treatment and placebo arms $(\mathrm{N}=28)$ 


\begin{tabular}{|c|c|c|c|}
\hline \multicolumn{4}{|l|}{ Baseline survey } \\
\hline & $\begin{array}{l}\text { Naproxen } \\
(n=14)\end{array}$ & $\begin{array}{l}\text { Placebo } \\
(n=14)\end{array}$ & $\begin{array}{l}P \\
\text { value }\end{array}$ \\
\hline Age in years & & & .9900 \\
\hline Mean & 29.3 & 29.3 & \\
\hline Range & $(23-35)$ & $(21-42)$ & \\
\hline \multirow[t]{2}{*}{ Body mass index $\left(\mathrm{kg} / \mathrm{m}^{2}\right)$} & Mean (SD) & Mean (SD) & .4776 \\
\hline & $23.7(5.6)$ & $25.1(4.2)$ & \\
\hline Race/ethnicity & $\mathrm{N}(\%)$ & $\mathrm{N}(\%)$ & $.2022 \rrbracket$ \\
\hline White & $12(85.7)$ & $11(78.6)$ & \\
\hline Asian & $1(7.1)$ & $2(14.3)$ & \\
\hline Other & $1(7.1)$ & $1(7.1)$ & \\
\hline Education & $\mathrm{N}(\%)$ & N (\%) & $.1290 \rrbracket$ \\
\hline High school or less & $1(7.1)$ & 0.0 & \\
\hline Some college & $3(21.4)$ & $5(35.7)$ & \\
\hline Bachelor's degree or higher & $10(71.4)$ & $9(64.3)$ & \\
\hline Employed & $\mathrm{N}(\%)$ & $\mathrm{N}(\%)$ & $.3370 \otimes$ \\
\hline Yes & $11(78.6)$ & $12(85.7)$ & \\
\hline Marital status & $\mathrm{N}(\%)$ & $N(\%)$ & $.2457 \rrbracket$ \\
\hline Single/divorced & $4(28.6)$ & $7(50)$ & \\
\hline Married/living with partner & $10(71.4)$ & $7(50)$ & \\
\hline Household income (annual) & $\mathrm{N}(\%)$ & $N(\%)$ & $.2688 \rrbracket$ \\
\hline$<\$ 10,000$ & 0.0 & $2(14.3)$ & \\
\hline$\$ 10,000-\$ 39,999$ & $9(64.3)$ & $5(35.7)$ & \\
\hline$\$ 40,000-74,999$ & $3(21.4)$ & $6(42.9)$ & \\
\hline Over $\$ 75,000$ & $2(14.3)$ & $1(7.1)$ & \\
\hline Parity & $\mathrm{N}(\%)$ & $\mathrm{N}(\%)$ & $1.000 \rrbracket$ \\
\hline Nulliparous & $11(78.6)$ & $11(78.6)$ & \\
\hline $1+$ & $3(21.4)$ & $3(21.4)$ & \\
\hline Menstrual cycle length in last 3 months & $\mathrm{N}(\%)$ & $\mathrm{N}(\%)$ & $.8342 \bigotimes$ \\
\hline$<24$ days & $1(7.7)$ & 0.0 & \\
\hline 24-31 days & $9(69.2)$ & $11(78.6)$ & \\
\hline 32-38 day & $2(15.4)$ & $2(14.3)$ & \\
\hline $39-50$ days & 0.0 & $1(7.1)$ & \\
\hline $51+$ days & $1(7.7)$ & 0.0 & \\
\hline \multirow[t]{2}{*}{ Days of bleeding/cycle in last 3 months } & Mean (SD) & Mean (SD) & .2515 \\
\hline & $3.5(1.0)$ & $5.6(6.8)$ & \\
\hline Amount of bleeding typically during menstruation & $\mathrm{N}(\%)$ & $\mathrm{N}(\%)$ & $.2166 \rrbracket$ \\
\hline Spotting/Light & $2(15.4)$ & 0.0 & \\
\hline Moderate & $7(53.9)$ & $6(42.9)$ & \\
\hline Heavy & $4(30.8)$ & $8(57.1)$ & \\
\hline Proportion who had naturally-induced periods vs. hormonally induced periods within 3 months & $\mathrm{N}(\%)$ & $\mathrm{N}(\%)$ & $.4401 \rrbracket$ \\
\hline
\end{tabular}




\begin{tabular}{|c|c|c|c|}
\hline Natural & $7(53.9)$ & $10(71.4)$ & \\
\hline Hormone-induced & $6(46.2$ & $4(28.6)$ & \\
\hline \multirow[t]{2}{*}{ Severity of pelvic pain at its worst during last 12 months } & Mean (SD) & Mean (SD) & .2592 \\
\hline & $3.3(1.1)$ & $4.1(2.5)$ & \\
\hline Amount of pain during LMP & $\mathrm{N}(\%)$ & $\mathrm{N}(\%)$ & $.7006 \bigotimes$ \\
\hline No pain & $3(21.4)$ & $2(14.3)$ & \\
\hline Mild cramps & $8(57.1)$ & $7(50.0)$ & \\
\hline Moderate cramps & $3(21.4)$ & $3(21.4)$ & \\
\hline Severe cramps & 0.0 & $2(14.3)$ & \\
\hline Birth Control method used prior to IUD placement** & $\mathrm{N}(\%)$ & $\mathrm{N}(\%)$ & \\
\hline Pills, patch or ring & $8(57.1)$ & $4(28.6)$ & .1266 \\
\hline Condoms & $6(42.9)$ & $9(64.3)$ & .2566 \\
\hline Hormonal IUD/Implant & $2(14.3)$ & $1(7.1)$ & $1.000 \bigotimes$ \\
\hline Other* & $4(28.6)$ & $5(35.7)$ & 1.000 \\
\hline
\end{tabular}

*Other=diaphragm, spermicide, withdrawal, abstinence (as reported by participants)

** May not add up to $100 \%$ since more than a single method may have been reported

$\nabla$ Fisher's exact test

\Chi-squared test

Table 2

Mean days of bleeding \& spotting, bleeding-only and spotting-only for 84-day treatment and 28-day post-treatment

\begin{tabular}{|c|c|c|c|c|c|c|c|c|c|c|c|c|c|c|c|}
\hline & \multicolumn{5}{|c|}{ Either bleeding or spotting days } & \multicolumn{5}{|c|}{ Bleeding only days } & \multicolumn{5}{|c|}{ Spotting only days } \\
\hline & \multirow[b]{2}{*}{$\begin{array}{l}\text { Mean } \\
\text { (SE) }\end{array}$} & \multicolumn{2}{|c|}{ Unadjusted } & \multicolumn{2}{|c|}{$\begin{array}{l}\text { Adjusted for } \\
\text { baseline } \\
\text { bleeding* }\end{array}$} & \multirow[b]{2}{*}{$\begin{array}{l}\text { Mean } \\
\text { (SE) }\end{array}$} & \multicolumn{2}{|c|}{ Unadjusted } & \multicolumn{2}{|c|}{$\begin{array}{l}\text { Adjusted for } \\
\text { baseline } \\
\text { bleeding* }\end{array}$} & \multirow[b]{2}{*}{$\begin{array}{l}\text { Mean } \\
\text { (SE) }\end{array}$} & \multicolumn{2}{|c|}{ Unadjusted } & \multicolumn{2}{|c|}{$\begin{array}{l}\text { Adjusted for } \\
\text { baseline } \\
\text { bleeding* }\end{array}$} \\
\hline & & $\begin{array}{l}\text { Mean } \\
\text { diff. } \\
(95 \% \\
\mathrm{Cl})\end{array}$ & $\begin{array}{l}\mathrm{p} \\
\text { value }\end{array}$ & $\begin{array}{l}\text { Mean } \\
\text { diff. } \\
(95 \% \\
\text { Cl) }\end{array}$ & $\begin{array}{l}\mathrm{p} \\
\text { value }\end{array}$ & & $\begin{array}{l}\text { Mean } \\
\text { diff. } \\
(95 \% \\
\text { Cl) }\end{array}$ & $\begin{array}{l}\mathrm{p} \\
\text { value }\end{array}$ & $\begin{array}{l}\text { Mean } \\
\text { diff. } \\
(95 \% \\
\mathrm{Cl})\end{array}$ & $\begin{array}{l}\mathrm{p} \\
\text { value }\end{array}$ & & $\begin{array}{l}\text { Mean } \\
\text { diff. } \\
(95 \% \\
\text { Cl) }\end{array}$ & $\begin{array}{l}\mathrm{p} \\
\text { value }\end{array}$ & $\begin{array}{l}\text { Mean } \\
\text { diff. } \\
(95 \% \\
\mathrm{Cl})\end{array}$ & $\begin{array}{l}\mathrm{p} \\
\text { value }\end{array}$ \\
\hline \multicolumn{16}{|c|}{ First 84 days } \\
\hline \multirow[t]{2}{*}{$\begin{array}{l}\text { Naproxen } \\
(n=12)\end{array}$} & \multirow[t]{2}{*}{$\begin{array}{l}29.2 \\
(4.5)\end{array}$} & $\begin{array}{l}+6.2 \\
(-4.9 \\
-\end{array}$ & \multirow[t]{2}{*}{0.31} & \multirow[t]{2}{*}{$\begin{array}{l}+9.8 \\
(-1.5- \\
21.2)\end{array}$} & \multirow[t]{2}{*}{0.11} & \multirow[t]{2}{*}{$\begin{array}{l}15.7 \\
(2.1)\end{array}$} & \multirow[t]{2}{*}{$\begin{array}{l}+0.2 \\
(-5.7- \\
6.1)\end{array}$} & \multirow[t]{2}{*}{0.96} & $\begin{array}{l}+2.7 \\
(-4.1- \\
9.5)\end{array}$ & \multirow[t]{2}{*}{0.44} & \multirow[t]{2}{*}{$\begin{array}{l}13.5 \\
(5.1)\end{array}$} & \multirow[t]{2}{*}{$\begin{array}{l}+6.0 \\
(-5.6- \\
17.6)\end{array}$} & \multirow[t]{2}{*}{0.28} & $\begin{array}{l}+9.1 \\
(-3.4- \\
21.7)\end{array}$ & \multirow[t]{2}{*}{0.14} \\
\hline & & 17.2) & & & & & & & & & & & & & \\
\hline $\begin{array}{l}\text { Placebo } \\
(n=8)\end{array}$ & $\begin{array}{l}23.0 \\
(2.8)\end{array}$ & & & & & $\begin{array}{l}15.5 \\
(1.8)\end{array}$ & & & & & $\begin{array}{l}7.5 \\
(1.7)\end{array}$ & & & & \\
\hline \multicolumn{16}{|c|}{ Last 28 days } \\
\hline $\begin{array}{l}\text { Naproxen } \\
(n=12)\end{array}$ & $\begin{array}{l}9.3 \\
(1.9)\end{array}$ & $\begin{array}{l}-0.3 \\
(-4.9- \\
4.2)\end{array}$ & 0.86 & $\begin{array}{l}0.7 \\
(-4.4 \\
-5.8)\end{array}$ & 0.78 & $\begin{array}{l}4.8 \\
(1.0)\end{array}$ & $\begin{array}{l}-1.8 \\
(-5.2- \\
1.4)\end{array}$ & 0.24 & $\begin{array}{l}-1.0 \\
(-4.5 \\
-2.4)\end{array}$ & 0.55 & $\begin{array}{l}4.5 \\
(2.0)\end{array}$ & $\begin{array}{l}+1.5 \\
(-3.1- \\
6.1)\end{array}$ & 0.50 & $\begin{array}{l}2.4 \\
(-2.9 \\
- \\
7.7)\end{array}$ & 0.34 \\
\hline $\begin{array}{l}\text { Placebo } \\
(n=8)\end{array}$ & $\begin{array}{l}9.6 \\
(0.9)\end{array}$ & & & & & $\begin{array}{l}6.6 \\
(1.2)\end{array}$ & & & & & $\begin{array}{l}3.0 \\
(0.8)\end{array}$ & & & & \\
\hline
\end{tabular}


*Missing 1 Naproxen case that did not report baseline bleeding days

Table 3

Self-respondent monthly questionnaire for the 84-day treatment and 28-day post-treatment $(\mathrm{N}=28)$

\begin{tabular}{|c|c|c|c|c|c|c|c|c|c|c|c|c|}
\hline & \multicolumn{3}{|c|}{ Moderate heavy/heavy periods } & \multicolumn{3}{|c|}{$\begin{array}{l}\text { Menstrual bleeding length } \\
7+\text { days }\end{array}$} & \multicolumn{3}{|c|}{ Often/always cramping } & \multicolumn{3}{|c|}{ Unexpected bleeding } \\
\hline & $\%$ & $\%$ diff. & $\mathrm{p}$ value & $\%$ & $\%$ diff. & $\mathrm{p}$ value & $\%$ & $\%$ diff. & $\mathrm{p}$ value & $\%$ & $\%$ diff. & $p$ value \\
\hline \multicolumn{13}{|l|}{ Month 1} \\
\hline Naproxen $(n=13)$ & 53.9 & 0 & 1.0 & 58.3 & +27.5 & 0.17 & 8.3 & -27.4 & $0.17 *$ & 46.2 & +7.7 & 0.69 \\
\hline $\begin{array}{l}\text { Placebo } \\
(n=14)\end{array}$ & 53.9 & & & 30.8 & & & 35.7 & & & 38.5 & & \\
\hline \multicolumn{13}{|l|}{ Month 2} \\
\hline $\begin{array}{l}\text { Naproxen } \\
(n=13)\end{array}$ & 30.8 & -30.7 & 0.12 & 61.5 & +19.8 & 0.32 & 8.3 & 0 & 1.0 & 53.9 & 0 & 1.0 \\
\hline $\begin{array}{l}\text { Placebo } \\
(n=13)\end{array}$ & 61.5 & & & 41.7 & & & 8.3 & & & 53.9 & & \\
\hline \multicolumn{13}{|l|}{ Month 3} \\
\hline Naproxen $(n=11)$ & 54.6 & -5.4 & $1.0^{*}$ & 54.6 & +9.1 & 0.67 & 9.1 & 0 & $1.0^{*}$ & 9.1 & -30.9 & $0.15^{\star}$ \\
\hline $\begin{array}{l}\text { Placebo } \\
(n=11)\end{array}$ & 60.0 & & & 45.5 & & & 9.1 & & & 40.0 & & \\
\hline \multicolumn{13}{|c|}{ Month 4 (non-treatment month) } \\
\hline $\begin{array}{l}\text { Naproxen } \\
(n=13)\end{array}$ & 61.5 & $+11.5 \%$ & 0.56 & 50.0 & +4.5 & 0.83 & 23.1 & +14.8 & $0.59 *$ & 38.5 & -3.2 & $1.0^{*}$ \\
\hline $\begin{array}{l}\text { Placebo } \\
(n=12)\end{array}$ & 50.0 & & & 45.5 & & & 8.3 & & & 41.7 & & \\
\hline
\end{tabular}

*Fisher's exact test

Table 4

Average number of days of symptoms reported for 84-day treatment period, by treatment group $(\mathrm{N}=20)$ 


\begin{tabular}{|llll|}
\hline & Naproxen $(\mathrm{n}=12)$ & Placebo $(\mathrm{n}=8)$ & -value \\
\hline Symptom & Mean \# of days (SD) & Mean \# of days (SD) & \\
\hline Headache & $3.8(6.4)$ & $2.6(4.5)$ & 0.67 \\
\hline Cramping & $7.3(9.8)$ & $4.9(3.8)$ & 0.46 \\
Nausea & $1.1(2.6)$ & $1.1(1.8)$ & 0.97 \\
\hline Vomiting & $0(0)$ & $0.1(0.4)$ & 0.35 \\
\hline Diarrhea & $0.1(0.3)$ & $0.4(0.7)$ & 0.32 \\
\hline Dizziness & $0(0)$ & $0.1(0.4)$ & 0.35 \\
\hline Other & $2.2(6.3)$ & $1.5(2.1)$ & 0.74 \\
\hline
\end{tabular}

\section{Table 5}

6-month patient satisfaction and certainty of continuing TCu380A IUD after study completion (N=25)

\begin{tabular}{|lll|}
\hline & Naproxen $(\mathrm{n}=13)$ & Placebo $(\mathrm{n}=12)$ \\
\hline Satisfaction Score* & Median (IQR) & Median (IQR) \\
\hline Plans to continue Copper IUD for next 6 months even if you...** & $3(2.25-3)$ \\
\hline Have side effects & $3(2.5-4)$ & $4(2-4)$ \\
\hline Break up with your partner & $4(3-4)$ & $4(4-4)$ \\
\hline Have extra spotting between periods & $4(3-4)$ & $4(3-4)$ \\
\hline Have heavy periods & $4(3-4)$ & $4(2.5-4)$ \\
\hline Have painful periods & $3(1-4)$ & $3(1.25-4)$ \\
\hline If your partner doesn't want you to use it & $4(2.5-4)$ & $4(3-4)$ \\
\hline
\end{tabular}

*based on 3-point Likert scale, 3=very satisfied, 2=somewhat satisfied, $1=$ not satisfied

**based on 4-point Likert scale, $4=$ very sure, $3=$ sure, $2=$ somewhat sure, $1=$ not sure at all, $0=$ don't know

$\mathrm{IQR}=$ interquartile range

\section{Figures}




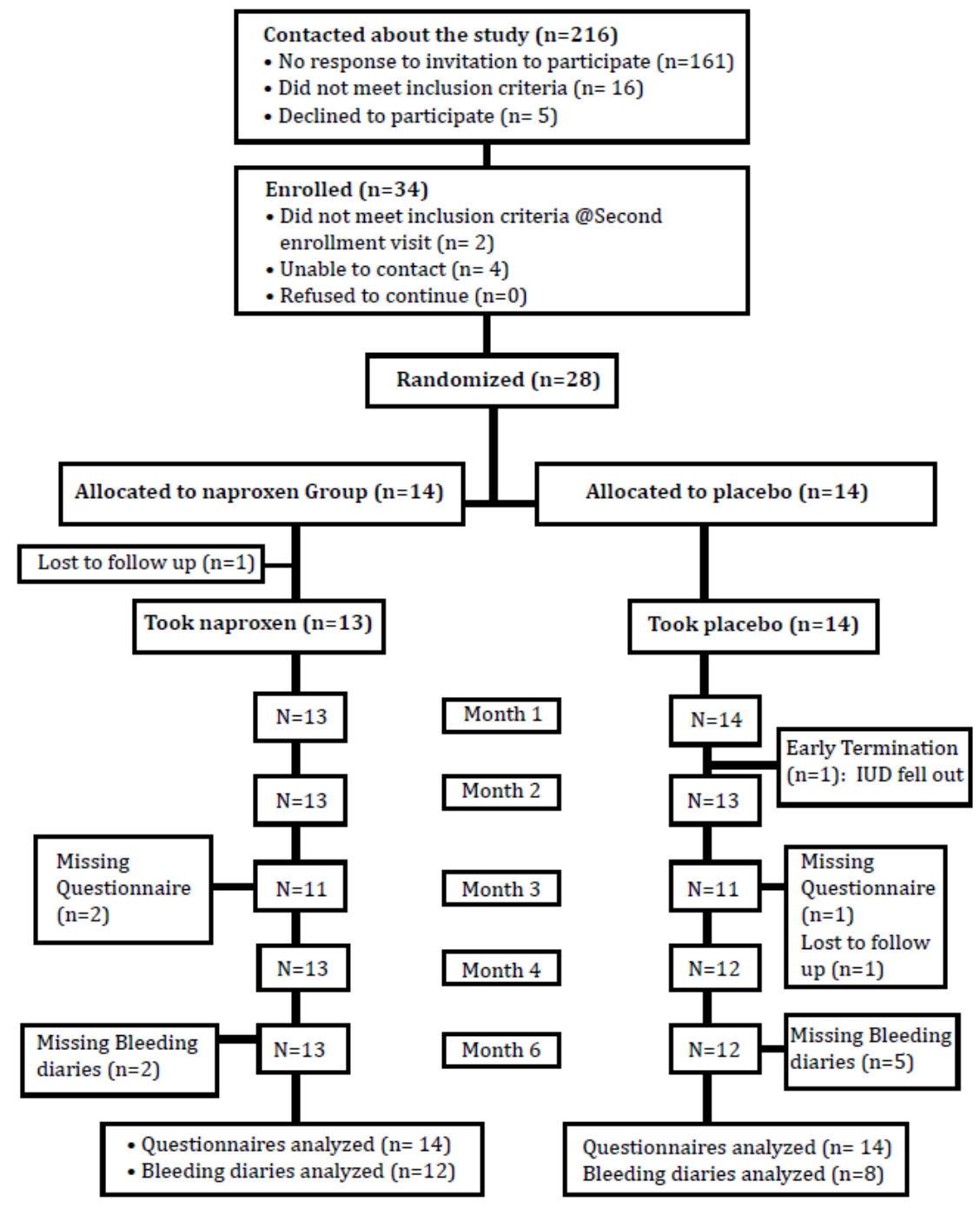

Figure 1

Participant flow according to CONSORT guidelines

\section{Supplementary Files}

This is a list of supplementary files associated with this preprint. Click to download.

- CONSORT2010ChecklistBMCWH.pdf 